\title{
Web-Based Patient Segmentation in Finnish Primary Care: Protocol for Clinical Validation of the Navigator Service in Patients With Diabetes
}

\author{
Riikka Riihimies $^{1,2}, \mathrm{MD}$; Elise Kosunen ${ }^{1}, \mathrm{MD}, \mathrm{PhD}$; Tuomas Koskela ${ }^{1,3}, \mathrm{MD}, \mathrm{PhD}$ \\ ${ }^{1}$ Faculty of Medicine and Health Technology, Tampere University, Tampere, Finland \\ ${ }^{2}$ Health Center, Valkeakoski, Finland \\ ${ }^{3}$ Center of General Practice, Pirkanmaa Hospital District, Tampere, Finland
}

Corresponding Author:

Riikka Riihimies, MD

Faculty of Medicine and Health Technology

Tampere University

PL 100

Tampere, 33014

Finland

Phone: 358505262556

Email: riikka.riihimies@tuni.fi

\begin{abstract}
Background: An aging population and increasing multimorbidity challenge health care systems worldwide. Patient segmentation aims to recognize groups of patients with similar needs, offer targeted services to these groups, and reduce the burden of health care. In this study, the unique Finnish innovation Navigator, a web-based service for patient segmentation, is presented. Both patients and health care professionals complete the electronic questionnaire concerning patients' coping in everyday life and health state. Thus, it considers the patient perspective on self-care. One of four customership-strategy (CS) groups (self-acting, community, cooperating, and network) is then proposed in response to the answers given. This resulting strategy helps both professionals to coordinate patient health care and patients to utilize appropriate health services.
\end{abstract}

Objective: This study aims to determine the feasibility, validity, and reliability of the Navigator service in the segmentation of patients with diabetes into four CS groups in a primary care setting. Patient characteristics concerning demographic status, chronic conditions, disabilities, health-related quality of life, and well-being in different CS groups will be described. We hypothesize that patients in the network group will be older, have more illnesses, chronic conditions or disabilities, and require more health care services than patients in the self-acting group.

Methods: In this mixed methods study, data collection was based on questionnaires (user experience of Navigator, demographic and health status, World Health Organization Disability Assessment Schedule 2.0, EuroQol 5D, Wellbeing Questionnaire 12, and the Diabetes Treatment Satisfaction Questionnaire) issued to 300 patients with diabetes and on user-experience questionnaires for and semistructured focus-group interviews with 12 nurses. Navigator-database reports and diabetes-care values (blood pressure, BMI, HbA1c, low-density lipoprotein, albumin-creatinine, smoking status) were collected. Qualitative and descriptive analyses were used to study the feasibility, content, concurrent, and face validity of Navigator. While criterion and concurrent validity were examined with correlations, reliability was examined by calculating Cohen kappa and Cronbach alpha. Construct validity is studied by performing exploratory-factor analysis on Navigator data reports and by hypothesis testing. The values, demographics, and health status of patients in different groups were described, and differences between groups were studied by comparing means. Linear regression analysis was performed to assess which variables affect CS group variation.

Results: Data collection was completed in September 2019, and the first feasibility results are expected by the end of 2020. Further results and publications are expected in 2021 and 2022.

Conclusions: This is the first scientific study concerning Navigator's psychometric properties. The study will examine the segregation of patients with diabetes into four CS groups in a primary care setting and the differences between patients in groups. This study will assist in Navigator's further development as a patient segmentation method considering patients' perspectives on self-care. This study will not prove the effectiveness or efficacy of Navigator; therefore, it is essential to study these outcomes of separate care pathways. 
International Registered Report Identifier (IRRID): DERR1-10.2196/20570

(JMIR Res Protoc 2020;9(11):e20570) doi: $\underline{10.2196 / 20570}$

\section{KEYWORDS}

patient segmentation; equality; health care services; coordination of care; primary care; Navigator; psychometric properties; questionnaires; eHealth

\section{Introduction}

Primary health care systems should deliver services equally for every patient, but an aging population and increasing multimorbidity challenge the capacity of health care systems worldwide [1-5]. Treatment of multiple medical conditions in different health care organizations may lead to fragmentation and incomplete coordination of care, and inefficiency, ineffectiveness, and inequality as unintended consequences of fragmented care [6,7]. Patients' unmet needs lead to poor health outcomes, inappropriate services, and rising costs $[1,8,9]$. Inequalities in health care appear owing to socioeconomic differences in health and the use of health care services [10-14]. In the 1970s, this was described as The Inverse Care Law [15-17]. One size does not fit all in health services, and one care pathway is not suitable for all patients.

Patient segmentation is an approach that aims to recognize groups of patients with similar health care needs and help care providers to develop services targeted to these groups [18-20]. The origin of patient segmentation was provided in 1970 by $\mathrm{Dr}$ Garfield at Kaiser Permanente when recognizing groups of the well, the worried well, early sick, and sick patients were introduced in the new approach to medical care delivery [21]. Another aspect of patient segmentation derives from the field of business and marketing, where, in addition to medical conditions, patients' needs, willingness, and self-efficacy to care are presented to be combined with the production logic of health care services [22,23].

Methods for patient segmentation are either data-driven, where data from different databases and/or electronic health records (EHR) are collected and statistically analyzed [24,25], or expert-driven, where an expert defines the criteria for segmentation [25,26]. The Senior Segmentation Algorithm is a segmentation tool developed at Kaiser Permanente and implemented in the EHR, utilizing EHR data, risk scores, and indicators [27]. Simple Segmentation Tool (SST) is for segmenting the aging population in Singapore and administered by the clinician $[28,29]$. Different patient segments have been based on medical condition or clinical criteria [30], patient utilization of services [31], and costs of health care [9,32], risk algorithms [33], difficulties in functioning [34], or a combination of factors $[29,35]$. However, none of these segmentation methods consider personal needs, values, or patients' conditions in individual care. When patient-centered care and health services are planned, patient's self-efficacy and everyday coping should be objectives [36-38]. Moreover, developing separate care pathways for different patient segments could help allocate health care professional resources to the most vulnerable patients and develop and target electronic services to patients capable of managing and navigating in health services.

In Finland, an innovation for patient segmentation has been developed that, remarkably, considers the patients' perspectives regarding their everyday life and self-care resources. Navigator (Suuntima in Finnish) is a web-based service for use at appointments. Both patients and health care professionals complete their electronic questionnaires during the conversation. While patients' questions measure their ability to function in everyday life, questions for professionals measure patients' health status or the degree of their diseases and treatments (Figure 1). As a result of these questions, one of four different customership-strategy (CS) groups is proposed: self-acting, community, cooperation, or network. Care pathways differ for each group, thus guiding professionals in coordinating patients' health services as appropriately as possible. The CS group-related care pathway aims to empower patients in self-care by helping them to utilize appropriate health services. The CS group does not guide a patient's medical treatment. The basis of "customership strategies" is in business and marketing; thus, the same terminology has been used here. In health care, the patient is the customer and the nurse or physician the professional. 
Figure 1. Dimensions of Navigator and four CS groups.

\section{Customership strategies}

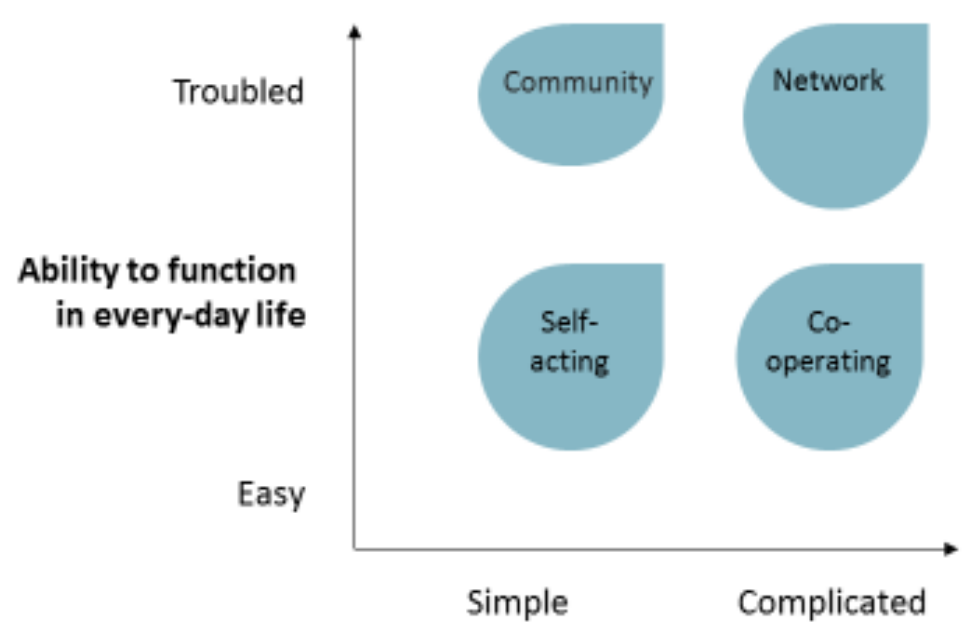

Health status or the degree of patients disease and treatment

Koivuniemi \& Simonen, Duodecim 2011

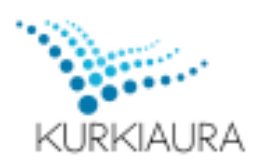

During Navigator's development, the model was piloted among patients with acute myocardial infarct and patients suffering from alcohol or drug abuse or mental disorders. Segregation of these patients left $60 \%-66 \%$ in self-acting, $10 \%-20 \%$ in the community, $10 \%-25 \%$ in cooperating, and $9 \%-10 \%$ in the network group.

Though Navigator is a general service and suitable to be used with patients with any chronic condition, diabetes was chosen as an example disease because it is a major, seriously complicated, and expensive chronic condition both in Finland and worldwide, requiring multiple medical services [39,40]. In 2019, diabetes was diagnosed in 463 million patients between 20-79 years, and it is estimated that the prevalence increases $51 \%$ globally, meaning 700 million patients with diabetes in 2045 [39]. Multifactorial barriers in patients' diabetes management are related to adherence and knowledge about diabetes, cultural aspects, comorbidities, financial resources, and social support [41]. Moreover, barriers in provider and health care systems influence self-care, and self-care barriers are related to complications with type 2 diabetes [42]. Thus, segmenting the vast population of patients with diabetes is essential, and Navigator service might help to recognize and exceed barriers in diabetes management.

This study is the first to address the Navigator service's psychometric properties and the segmentation of patients into CS groups. This study aims to examine the feasibility of
Navigator at nursing appointments with patients with diabetes at the health center, study the validity and reliability of Navigator, and characterize patients in each of the four CS groups. The hypothesis is that patients assigned to the network group will be older, more multimorbid and disabled than are patients in the self-acting group.

The detailed research questions are:

1. How user-friendly and time-consuming is Navigator as a web-based service at ordinary appointments, and does it add new issues to nurse-patient discussions (feasibility)? Does Navigator-based segmentation differ from current practice (intuition) in evaluating patient-specific health care service needs (criterion validity)?

2. Are questions studying the health status or everyday ability of patients to function relevant, sufficiently comprehensive, and comprehensible (content validity)?

3. Do all of Navigator's items measure the same construct (internal consistency, reliability), and are all its questions necessary (construct validity)?

4. Is the CS-group segregation result repeatable after two-to-three weeks (test-retest) with the same professional (intrarater) or between professionals (interrater reliability)?

5. How are patients with diabetes segregated in a primary care setting, and what kinds of patients inhabit different CS groups? 


\section{Methods}

\section{Study Design}

This mixed methods study combines qualitative and quantitative methods. Data collection is based on questionnaires for nurses and patients with diabetes, focus group interviews for nurses, the medical parameters of diabetes care, and Navigator reports from the Pirkanmaa Hospital District database (Figure 2). The study population of 300 patients and 12 nurses were recruited at Valkeakoski social and health center.
COSMIN criteria (consensus-based standards for selecting health-measurement instruments), and quality criteria for the measurement properties of health status questionnaires, were used as a methodological framework to study the content, construct, and criterion validity as well as the reliability of Navigator [43,44]. Patient-reported outcome measures have been developed to capture patients' views on the effect of illnesses and symptoms in their everyday lives and assist communication and decision-making in care between doctors and patients [45]. In this study, Navigator is examined as a patient-reported outcome measure.

Figure 2. Psychometric properties of Navigator, data collection methods and statistical analysis used in study, and timeline of data collection process.

\begin{tabular}{|c|c|c|c|c|c|}
\hline $\begin{array}{l}\text { PSYCHOMETRIC } \\
\text { PROPERTY }\end{array}$ & $\begin{array}{l}\text { Feasibility } \\
\text { Content validity } \\
\text { Face validity }\end{array}$ & $\begin{array}{l}\text { Criterion validity } \\
\text { Concurrent validity }\end{array}$ & $\begin{array}{l}\text { Reliability } \\
\text { (test-retest, } \\
\text { intra-rater, } \\
\text { inter-rater) }\end{array}$ & $\begin{array}{l}\text { Internal } \\
\text { consistency }\end{array}$ & $\begin{array}{l}\text { Construct validity } \\
\text { (structural validity, } \\
\text { hypothesis testing) }\end{array}$ \\
\hline $\begin{array}{l}\text { DATA } \\
\text { COLLECTION } \\
\text { METHOD }\end{array}$ & $\begin{array}{l}\text { User-experience } \\
\text { questionnaires } \\
\text { for nurses and } \\
\text { patients } \\
\text { Semi-structured } \\
\text { focus-group } \\
\text { interviews } \\
\text { for nurses }\end{array}$ & $\begin{array}{l}\text { Nurse's evaluation } \\
\text { of patient's CS group } \\
\text { prior to appointment }\end{array}$ & $\begin{array}{l}2^{\text {nd }} \text { Navigator } \\
\text { at GPs appt } \\
\text { with the same nurse } \\
\text { as } 1^{\text {st }} \text { Navigator } \\
\text { and } \\
\text { research assistant }\end{array}$ & $\begin{array}{l}\text { Navigator } \\
\text { database } \\
\text { reports }\end{array}$ & $\begin{array}{l}\text { Demographics and } \\
\text { health status } \\
\text { questionnaire, } \\
\text { EQ-5D } \\
\text { WHODAS } 2.0 \\
\text { WBQ-12 } \\
\text { DTSQ } \\
\text { DM treatment } \\
\text { measures }\end{array}$ \\
\hline $\begin{array}{l}\text { STATISTICAL } \\
\text { ANALYSIS }\end{array}$ & $\begin{array}{l}\text { Qualitative } \\
\text { and } \\
\text { descriptive } \\
\text { Analysis }\end{array}$ & Correlations & $\begin{array}{l}\text { Cohen's } \\
\text { kappa }\end{array}$ & $\begin{array}{l}\text { Cronbach's } \\
\text { alfa }\end{array}$ & $\begin{array}{l}\text { Hypothesis testing } \\
\text { Factor analysis }\end{array}$ \\
\hline \multicolumn{2}{|c|}{$\begin{array}{l}\text { 1-3 weeks before appt } \\
\text { Patient recruitment ( } \mathrm{n}=300) \\
\text { (age }>18, \mathrm{DM} \mathrm{dg} \text {, nurse's appt concerning DM care) } \\
\text { contact by phone and } \\
\text { informed consent posted for patients } \\
\text { willing to participate the study }\end{array}$} & $\begin{array}{c}\text { At the nurses appt } \\
1^{\text {st }} \text { Navigator } \\
\text { Questionnaires }\end{array}$ & $\begin{array}{l}\text { After 2-3 weeks } \\
2^{\text {nd }} \text { Navigator }\end{array}$ & & $\begin{array}{l}\text { Data collection } \\
\text { DM treatment } \\
\text { measures from EHR's } \\
\text { (HbA1c, LDL, } \\
\text { cU-ALbKre) } \\
\text { Navigator reports } \\
\text { Focus-group interviews }\end{array}$ \\
\hline
\end{tabular}

\section{Feasibility, Criterion and Concurrent Validity, Content and Face Validity}

Data are gathered with questionnaires for patients and nurses and semistructured focus group interviews for nurses.

The self-generated user-experience questionnaire for patients studies the CS group and the patient's opinion of the care pathway related to it through the Likert scale (from 1, meaning "complete agreement" to 5, meaning "complete disagreement"). Questions determine whether or not any help was needed, for example, from spouses, in answering Navigator's questions. Seven statements study whether questions were easy or difficult or took too long to answer. Statements include that patients' questions helped patients consider their life and everyday coping from a new perspective, that professionals' questions helped patients understand their life situation, and wish to continue to use Navigator in planning their health care services. Furthermore, open questions study whether or not patients disagreed with their CS group allocation and whether new issues concerning their everyday life appeared in the discussion because of the Navigator's questions.

Nurses fill out their user experience questionnaire after every patient with whom Navigator is used. It queries the time spent answering Navigator's questions and whether or not patients required assistance to answer them. Both nurses' and patients' views of Navigator results are queried by way of the Likert scale. Open questions gather information on whether or not, and how, nurses' or patients' views differed regarding CS group allocation. The questionnaire also studies nurse intuition regarding CS group allocation with every patient. The questionnaire queries nurses' previous contact with patients by phone or at appointments during the past year. These questions assess the criterion and the concurrent validity of Navigator.

Another questionnaire collects nurses' experience and work history in primary care and their prior knowledge of 
customership strategies. Opinions are obtained using a Likert scale to address Navigator's suitability for patient segregation and the usability of its results in coordinating care for patients with long-term conditions. Nine claims study whether or not the Navigator service was easy and suitable to use, and whether or not questions were too ambiguous or broad to be answered using the Visual Analog Scale (VAS). Users are also asked whether or not Navigator's questions were difficult to understand, helped raise difficult issues with patients, and helped professionals understand the patients' general care at a deep level. The final query is the plausibility of using Navigator and whether new issues appeared in the discussion via its use. Open questions specify if any of Navigator's questions were difficult to understand or too broad. Additionally, nurses are asked to describe if using Navigator was difficult or time-consuming with certain kinds of patients. This questionnaire examines the feasibility and the content validity of Navigator.

Semistructured interviews for three focus groups of four-to-five nurses will be performed after two-to-three months of Navigator use for assessing a more detailed user experience to study the feasibility, the content, and the face validity of Navigator (Multimedia Appendix 1). Interviews will be recorded and transcribed verbatim by an official service provider, and the research team will analyze written material.

\section{Construct Validity}

Construct validity consists of structural validity and hypothesis testing. Navigator measures two different constructs: patients' coping in everyday life and patient health status. These two different constructs are evaluated separately. All answers to each Navigator question on the VAS of 1 to 10 are saved in a Pirkanmaa Hospital District database. This information is collected as "Navigator reports."

Questionnaires examine data concerning patients' demographics, medical condition, health-related quality of life, and coping in everyday life.

A self-generated questionnaire is used to collect patient demographics and health status. Patient gender, year of birth, marital status, education, and employment situation is queried. Health-related questions concern self-rated health, duration with a diabetes diagnosis, diabetes medication, knowledge of target values for individual diabetes care, other illnesses or chronic conditions, and medication. Also queried are smoking status, alcohol usage, height and weight, tools needed for physical disability assistance, and the receipt of disability benefits or care allowance for pensioners from the Social Insurance Institution of Finland.

The WHODAS 2.0 (World Health Organization Disability Assessment Schedule 2.0) self-administered 12-item version is used to study health-related disability during the last 30 days. Twelve questions concerning six domains of function (cognition, mobility, self-care, getting along, life activities, and participation) are answered on a 5-point scale ranging from "no difficulties" to "extreme difficulties or could not" [46].

EuroQol 5D (EQ-5D) is a generic health-status measure consisting of the EQ-5D-5L descriptive system and measuring five dimensions of health (mobility, self-care, usual activities, pain/discomfort, and anxiety/depression), with each dimension having five response levels from "no problems" to "extreme problems or unable to." The EQ VAS measures the patient's self-rated health on a vertical VAS whose endpoints are respectively "The best health you can imagine" and "The worst health you can imagine." Patients are asked to evaluate their health on that day. The EQ-5D has Finnish Population Norms [47].

W-BQ12 is a general 12-item well-being questionnaire measuring negative well-being, energy, positive well-being, and general well-being. Patients evaluate their well-being during recent weeks on a 4-point scale from 0 (not at all) to 3 (all the time) [48].

Diabetes-treatment satisfaction questionnaires (DTSQs) are used to collect data on diabetes treatment satisfaction [49].

Medical parameters concerning diabetes care $\left(\mathrm{HbA}_{1 \mathrm{c}}\right.$, low-density lipoprotein, albumin-creatinine, blood pressure) are evaluated annually according to the Finnish Current Care Guideline for diabetes [50]. Values are collected from patients' medical records.

\section{Reliability}

During the nurse's appointment, Navigator is used for the first time, and the first CS group result is generated. Based on the patient's condition and self-care capability, the nurse then evaluates the patient's need for a physician appointment. Usually, a physician appointment is made with a physician-researcher within 3 weeks. At the beginning of the physician-researcher appointment, Navigator is used for the second time, with the same nurse, the physician, and a research assistant present (2018). All professionals complete their questionnaires independently, and three different results are generated.

\section{Study Population}

Patients with diabetes ( $\mathrm{n}=300$ based on sample size calculation) were recruited in a primary care setting at Valkeakoski health center. Annual follow-up visits concerning diabetes care are carried out at appointments with first a nurse and then if needed, a physician within a month. Twelve nurses working at Valkeakoski health center at the time of data collection were recruited for the study.

\section{Inclusion and Exclusion Criteria}

The inclusion criteria are age exceeding 18 years and a planned annual diabetes care follow-up appointment with a health center nurse. Exclusion criteria are patient disability preventing informed consent for participation in research (eg, Alzheimer disease, intellectual disability) and nonfluency with the Finnish language.

\section{Recruitment}

Patients scheduled for an annual diabetes-control appointment with a nurse within three weeks were identified via the electronic patient record system. They were then contacted in advance by phone and informed about the study. Patients willing to read further about the study were sent the informed consent 
declaration form by post. Recruitment began in October 2018 and was completed in September 2019.

\section{Data Collection}

Before the appointment with a recruited patient begins, the nurse is asked to evaluate the patient's Navigator result intuitively based on knowledge of the patient and medical records (Figure 2). Intuition-based results will also be collected from patients refusing to participate in the study.

At the beginning of the appointment, the nurse confirms the patient's participation, collects the signed consent form, and combines the patient's social security number with their study identification code. All data is encoded for processing, protecting patients and nurses from identification. Patients also receive the study envelope containing study questionnaires. Then the Navigator is used for the first time.

Navigator is used for the second time at the physician-researcher appointment, and diabetes treatment measures are collected. Measures for patients who receive no physician-researcher appointments are collected separately from medical records.

Semistructured interviews for three focus groups of nurses will be performed after Navigator has been used for two or three months, after which Navigator reports are gathered from the database.

\section{Intervention}

\section{Development of the Navigator Service}

The Navigator service was developed in collaboration with the Finnish Heart Association (FHA) and the Center of General Practice of Pirkanmaa Hospital District in the Kurkiaura project between 2011 and 2015. Navigator was produced by the FHA and is maintained by the Center of General Practice of Pirkanmaa Hospital District in Finland.

The development process began by describing different kinds of patients based on lifestyle studies. Patient stories describe how different individuals manage private matters and how capable they are of practicing self-care. Professional views of patient care, combined with patients' personal views of self-care, helped to develop the idea of a fourfold table. Issues limiting self-care were studied in a survey of patients with acute myocardial infarct and led to the implementation of separate care pathways for different patient classes. The need then arose to develop a tool to segregate patients into different segments, considering both patient and professional perspectives.

Questions in quality-of-life measurements (eg, 15D) and the international classification of functioning, disability, and health (ICF), were familiarized and reflected upon with previous patient stories to develop themes for patients' questions. Preliminary questions for patients were made and further developed in workshops with patients. A multiprofessional health care group suggested questions for professionals. Questions were agreed upon and further developed in meetings with multiprofessional health care experts (personal communication AR, LK).

\section{Content of the Navigator Service}

A 10-question patient and 8-question professional VAS are used (Multimedia Appendix 2, Figure 3). Answers on a scale of 1 to 10 are dichotomized at a certain cut point. The result of all answers is used to propose a CS group appropriate for each patient. Every CS group has its own care pathway, defining the focus of individual care plans, service and care coordinators, making appointments and contacting health care services, and alternatives to appointments and services typically included in certain pathways.

Figure 3. Navigator's first three questions for patients, showing VAS.

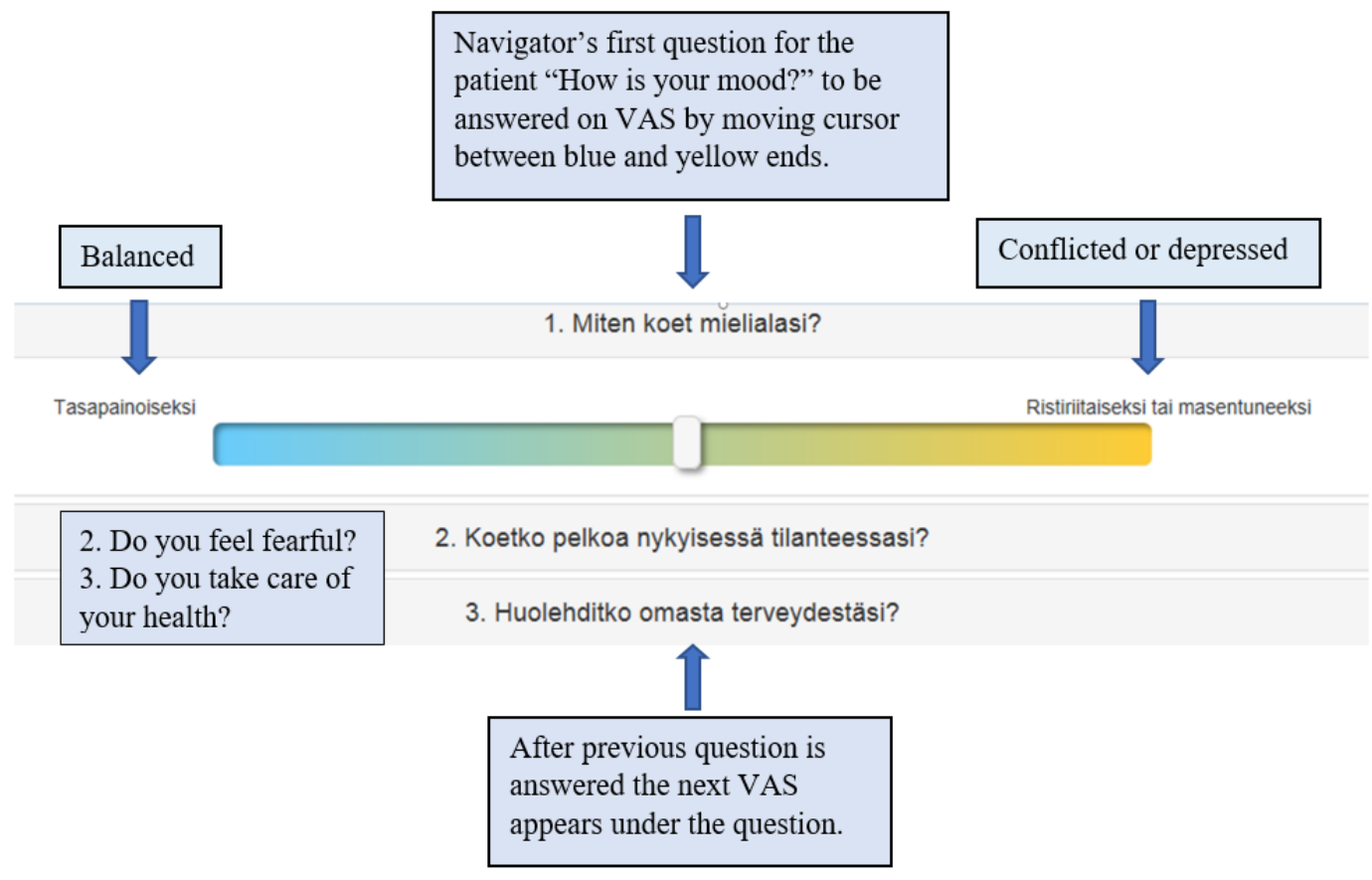




\section{Customership Strategy Groups and Care Pathways}

\section{Self-Acting Group}

Patients in the self-acting group competently manage everyday life with their illnesses and independently coordinate their health care. Health care services aim to support self-care in maintaining the ability to work and function. The individual health care plan for this group is focused on self-care. Planning alternative forms of health care services such as telemedicine options in contacts or as an alternative to appointments is essential with these patients who, according to pilots, make up the majority of all patients.

\section{Community Group}

The everyday life of patients in the community group is troubled, although their health status appears simple. Their individual health care plans focus on motivating and empowering their self-care, guiding them to peer group meetings, and building confidential health care relationships. The care coordinator could be a nurse who contacts the patient proactively, such as by phone, and organizes occasional appointments to ensure the appropriate use of health care services.

\section{Cooperating Group}

Patients in the cooperating group function in everyday life despite complicated health status. Their individual care plans focus on improving their ability to function and prevent complications and additional illnesses. The coordination of multiprofessional care and appointments is needed, and the coordinator is a health care professional. Electronic health care options could be used in contact with health care services.

\section{Network Group}

Patients in the network group are the most vulnerable and in need of intensive support. Their individual health care plans focus on maintaining the ability to function in everyday life at home and preventing hospitalization. Health care is proactive and usually multiprofessional. Services are coordinated by a professional, home visits are considered alternatives to appointments at the health center, and family support is essential.

\section{Sample Size}

Sufficient patient population and sample size calculations are needed to compare outcomes of patient variables in different CS groups. The power calculation is based on the WHODAS 2.0 validation study of patients with chronic conditions in Europe. The results of a 36-item WHODAS 2.0 questionnaire gave a mean score of 24.8 (complex scoring scale $0.00-93.5$ ) and a standard deviation of 19.3 [46]. No information on the 12-item WHODAS 2.0 questionnaire results in patients with diabetes was found for this purpose. Using a power of $80 \%$ and statistical significance of $P=.05$, a minimum of 30 patients are needed in each group, as the clinically significant difference between means of separate groups is assumed to be 14 on the WHODAS 2.0 scale (complex scoring 0.00-100). The effect size is moderate $(d=0,725)$ [51]. In Navigator pilots, the smallest group (9\%-10\% of patients) was the network group, resulting in a total sample size of 300 patients. A sample size calculator was used for the calculation [52].

\section{Statistical Analysis}

Feasibility, content, and face validity are examined with patient and professional user experience questionnaires and semistructured focus group interviews for professionals. Data analysis will be qualitative and descriptive. Qualitative thematic analysis will be used to analyze focus group interviews [53].

Criterion and concurrent validity are assessed, comparing nurse-intuited patient CS group allocation to the patient CS group allocation proposed by Navigator. Correlations can be calculated, and visible differences described.

Construct validity consists of structural validity and hypothesis testing. Navigator measures two constructs: the ability to cope in everyday life and patient health, and they are evaluated separately. Exploratory factor analysis is performed on each Navigator data report to evaluate how different factors are loaded. The assumption is that every question is important for determining either patient's coping in everyday life or the patient's health status. Descriptive statistics will be performed on patient values (demographic and health status, diabetes mellitus treatment measures, EQ-5D, WHODAS 2.0, WBQ-12, and DTSQ questionnaire responses) in different CS groups, and differences between groups will be studied by comparison of means. Linear-regression analysis is performed to assess which variables affect variation in CS-group allocation.

Intrarater, interrater, and test-retest reliability are analyzed by calculating Cohen kappa correlations between the first and second Navigator results obtained with the same nurse, in the presence of a physician and a research assistant. The internal consistency of items for both constructs will be analyzed by calculating Cronbach alpha.

\section{Ethical Approval}

The Tampere University Hospital Ethics Committee approved this study's ethical aspects in October 2018 (ETL R18070). Data collection at Valkeakoski Health Center was approved by head physician Myllynen in September 2018.

\section{Results}

Descriptive results of strengths, difficulties, and time spent using the Navigator service during nurses' appointments may help develop user instructions.

The results of patient segmentation into different CS groups may strengthen the results of previous pilot studies. The characteristics and differences of patients between groups are assumed to relate to Navigator's results: patients managing well in everyday life (self-acting and cooperating groups) could have better results in WHODAS 2.0, EQ-5D, and WBQ-12 than do patients with difficulties in everyday life. Moreover, patients in self-acting and community groups, whose health status is simpler than that of cooperating- and network-group patients, could have fewer chronic conditions, require less medication, and enjoy more successful diabetes mellitus treatment measures.

Exploratory factor analysis may indicate identifiable factors in patients' and professionals' questions. This outcome of construct validity may be used in further developing Navigator's items and be confirmed in future studies. 
Correlations between the test and retest results of Navigator will be statistically analyzed using the Cohen kappa coefficient. The reliability outcome is moderate if values are $0.41-0.60$, substantial if they are 0.61-0.80, and in almost perfect agreement if they are 0.81-1.00 [54]. In addition, how both patients' and professionals' questions measure the same construct helps assess the reliability and internal consistency of Navigator. Usually, internal consistency is high if Cronbach alpha is $>0.7$ (values between 0 and 1) [55].

\section{Discussion}

\section{Principal Findings}

This study is the first to assess the feasibility, validity, and reliability of Navigator, the Finnish innovation for patient segmentation. The study also examined the segregation of patients with diabetes into four customership groups in a primary care setting and the differences between patients in each group.

The Navigator service adds a patient's individual perspective of his/her ability to cope in everyday life to the methods of patient segmentation. EHR databases do not contain information pertinent to patients' capacity to navigate between health services. Therefore, discussing these issues with patients is essential when individual and patient-centered care is planned.

Patient navigation is described as barrier reduction and as 'a bridge over gaps in services' method. Facilitating access to care, communicating with multiple agencies in fragmented health and social care, and navigator persons such as health care professionals, case managers, or laypersons have been reviewed in diverse settings [56,57]. The Navigator service standardizes individual recognition of patients with different needs, and separate care pathways developed for different CS groups help patients navigate between health services.

Note that this study does not assess the effectiveness or efficacy of the four separate care pathways that Navigator proposes. In the future, it will be essential to study how efficient Navigator is in patient navigation and how it affects patient health outcomes.

\section{Risks and Biases}

Although several health centers in the Pirkanmaa region have been trialing the Navigator service with patients with different chronic conditions, it has yet to be properly implemented in health care use. Moreover, care pathways related to Navigator CS groups in different chronic conditions remain in development. Therefore, multicenter patient recruitment and regional data collection were unobtainable, and the study population was ultimately drawn from a single health center in Valkeakoski.

The study setting in health care services and particularly exclusion criteria may bias the study population and group segregation. Vulnerable patients may fail to familiarize themselves with the declaration of informed consent, leading to their refusal to participate in the study. In addition, vulnerable patients may not be treated in the health center's ambulatory diabetic guidance clinic, and thus their proportion of the total participants may be low. Furthermore, making appointments at health centers requires an ability to personally deal with the health care system that many vulnerable patients may lack. Nurses' intuitive evaluation of the customership of patients not participating in the study is also collected in order to assess this bias. Moreover, the self-selection bias of participants may impact results.

\section{Timetable and Publications}

Data collection was completed in September 2019. Analysis of Navigator user experiences and focus group interviews were performed in Spring 2020. The feasibility assessment of Navigator is expected to be completed in 2020. Further analysis of the psychometric properties of Navigator is expected in 2021, and the results of patient segregation and outcomes in different CS groups are expected in 2022. Further publications are expected in 2020-2022, with a $\mathrm{PhD}$ thesis expected to be completed in 2022 .

\section{Acknowledgments}

The Center of General Practice in the Pirkanmaa, City of Tampere, and General Practitioners in Finland.

Health Psychology Research provided a license to use the WBQ-12 and DTSQs questionnaires.

The authors would like to thank Anna Rikala (AR) and Leena Kuusisto (LK) for interviews concerning the development of the Navigator service; Sari Mäkinen and Leena Kuusisto for practical help in the Navigator study permission process and for delivering Navigator reports from the Pirkanmaa Hospital District database. At the Valkeakoski health center, Elina Kontiainen and Niina Kokkola assisted in organizing the data collection process. Biostatistician Mika Helminen helped with sample size and power calculations.

\section{Conflicts of Interest}

TK is a part-time salaried employee, and EK is a former part-time salaried employee of the Center of General Practice in Pirkanmaa. They were not involved in the development of Navigator.

\section{Multimedia Appendix 1}

Content of the semi-structured focus-group interview for nurses. [DOCX File, 15 KB-Multimedia Appendix 1] 


\section{Multimedia Appendix 2}

Navigator service's questions for patient and professional (translated in English by RR).

[DOCX File, 15 KB-Multimedia Appendix 2]

\section{References}

1. National Institute of Aging, National Institutes of Health, US Department of Health and Human Services. Global Health and Aging. Geneva: World Health Organization; 2011 Oct. URL: https://www.who.int/ageing/publications/global health. pdf [accessed 2020-07-14]

2. Multimorbidity: Technical Series on Safer Primary Care. Geneva: World Health Organization; 2016.

3. GBD 2017 Disease and Injury Incidence and Prevalence Collaborators. Global, regional, and national incidence, prevalence, and years lived with disability for 354 diseases and injuries for 195 countries and territories, 1990-2017: a systematic analysis for the Global Burden of Disease Study 2017. Lancet 2018 Dec 10;392(10159):1789-1858 [FREE Full text] [doi: 10.1016/S0140-6736(18)32279-7] [Medline: 30496104]

4. Garin N, Koyanagi A, Chatterji S, Tyrovolas S, Olaya B, Leonardi M, et al. Global Multimorbidity Patterns: A Cross-Sectional, Population-Based, Multi-Country Study. J Gerontol A Biol Sci Med Sci 2016 Feb;71(2):205-214 [FREE Full text] [doi: 10.1093/gerona/glv128] [Medline: 26419978]

5. Smith SM, Soubhi H, Fortin M, Hudon C, O'Dowd T. Managing patients with multimorbidity: systematic review of interventions in primary care and community settings. BMJ 2012;345:e5205. [Medline: 22945950]

6. Stange KC. The problem of fragmentation and the need for integrative solutions. Ann Fam Med 2009;7(2):100-103 [FREE Full text] [doi: 10.1370/afm.971] [Medline: 19273863]

7. Bodenheimer T. Coordinating care--a perilous journey through the health care system. N Engl J Med $2008 \mathrm{Mar}$ 6;358(10):1064-1071. [doi: 10.1056/NEJMhpr0706165] [Medline: $\underline{18322289}$ ]

8. Coster JE, Turner JK, Bradbury D, Cantrell A. Why Do People Choose Emergency and Urgent Care Services? A Rapid Review Utilizing a Systematic Literature Search and Narrative Synthesis. Acad Emerg Med 2017 Sep;24(9):1137-1149 [FREE Full text] [doi: 10.1111/acem.13220] [Medline: 28493626]

9. Wammes JJG, van der Wees PJ, Tanke MAC, Westert GP, Jeurissen PPT. Systematic review of high-cost patients' characteristics and healthcare utilisation. BMJ Open 2018 Sep 08;8(9):e023113. [doi: 10.1136/bmjopen-2018-023113] [Medline: $\underline{30196269}$ ]

10. Mackenbach JP, Stirbu I, Roskam AR, Schaap MM, Menvielle G, Leinsalu M, et al. Socioeconomic inequalities in health in 22 European countries. N Engl J Med 2008 Jun 5;358(23):2468-2481. [doi: 10.1056/NEJMsa0707519] [Medline: $\underline{18525043]}$

11. Dimitrovová K, Perelman J. Changes in access to primary care in Europe and its patterning, 2007-12: a repeated cross-sectional study. Eur J Public Health 2018 Jun 01;28(3):398-404 [FREE Full text] [doi: 10.1093/eurpub/cky019] [Medline: 29452396]

12. Manderbacka K, Arffman M, Keskimäki I. Has socioeconomic equity increased in somatic specialist care: a register-based cohort study from Finland in 1995-2010. BMC Health Serv Res 2014 Sep 24;14:430 [FREE Full text] [doi: 10.1186/1472-6963-14-430] [Medline: 25253175]

13. Virtanen P, Kivimäki M, Vahtera J, Koskenvuo M. Employment status and differences in the one-year coverage of physician visits: different needs or unequal access to services? BMC Health Serv Res 2006 Oct 02;6:123 [FREE Full text] [doi: 10.1186/1472-6963-6-123] [Medline: 17014702]

14. Frølich A, Ghith N, Schiøtz M, Jacobsen R, Stockmarr A. Multimorbidity, healthcare utilization and socioeconomic status: A register-based study in Denmark. PLoS One 2019;14(8):e0214183 [FREE Full text] [doi: 10.1371/journal.pone.0214183] [Medline: $\underline{\text { 31369580] }}$

15. Hart TJ. The Inverse Care Law. The Lancet 1971 Feb;297(7696):405-412 [FREE Full text] [doi: 10.1016/s0140-6736(71)92410-x]

16. Watt G. The inverse care law today. Lancet 2002 Jul 20;360(9328):252-254 [FREE Full text] [doi: 10.1016/S0140-6736(02)09466-7] [Medline: 12133675]

17. Mercer SW, Guthrie B, Furler J, Watt GCM, Hart JT. Multimorbidity and the inverse care law in primary care. BMJ 2012 Jun 19;344:e4152 [FREE Full text] [doi: 10.1136/bmj.e4152] [Medline: 22718915]

18. Vuik SI, Mayer EK, Darzi A. Patient Segmentation Analysis Offers Significant Benefits For Integrated Care And Support. Health Aff (Millwood) 2016 May 01;35(5):769-775 [FREE Full text] [doi: 10.1377/hlthaff.2015.1311] [Medline: 27140981]

19. Chong JL, Matchar DB. Benefits of Population Segmentation Analysis for Developing Health Policy to Promote Patient-Centred Care. Ann Acad Med Singap 2017 Jul;46(7):287-289 [FREE Full text] [Medline: 28821893]

20. Koivuniemi K. Holmberg-Marttila D. In: Hirsso P. Mattelmäki U. Terveydenhuollon kompassi - avain asiakkuuteen. Duodecim. Helsinki: Kustannus Oy Duodecim; 2014:2014.

21. Garfield SR. The Delivery of Medical Care: Medical care in the US is expensive and poorly distributed, and national health insurance will make things worse. What is needed is an innovative system in which the sick are separated from the well. The Permanente Journal 2006;10(2):46-56 [FREE Full text] [Medline: 21519441] 
22. Brommels M. Patient Segmentation: Adjust the Production Logic to the Medical Knowledge Applied and the Patient's Ability to Self-Manage-A Discussion Paper. Front Public Health 2020;8:195 [FREE Full text] [doi: 10.3389/fpubh.2020.00195] [Medline: $\underline{32537449]}$

23. Peltokorpi A, Linna M, Malmström T, Torkki P, Lillrank PM. Five focus strategies to organize health care delivery. Int J Health Care Qual Assur 2016;29(2):177-191 [FREE Full text] [doi: 10.1108/IJHCQA-05-2015-0065] [Medline: 26959897]

24. Yan S, Kwan YH, Tan CS, Thumboo J, Low LL. A systematic review of the clinical application of data-driven population segmentation analysis. BMC Med Res Methodol 2018 Nov 03;18(1):121 [FREE Full text] [doi: 10.1186/s12874-018-0584-9] [Medline: $\underline{30390641]}$

25. Chong JL, Lim KK, Matchar DB. Population segmentation based on healthcare needs: a systematic review. Syst Rev 2019 Aug 13;8(1):202 [FREE Full text] [doi: 10.1186/s13643-019-1105-6] [Medline: 31409423]

26. Low LL, Kwan YH, Ma CA, Yan S, Chia EHS, Thumboo J. Predictive ability of an expert-defined population segmentation framework for healthcare utilization and mortality - a retrospective cohort study. BMC Health Serv Res 2019 Jun 20;19(1):401 [FREE Full text] [doi: 10.1186/s12913-019-4251-6] [Medline: 31221139]

27. Zhou YY, Wong W, Li H. Improving care for older adults: a model to segment the senior population. Perm J 2014;18(3):18-21 [FREE Full text] [doi: 10.7812/TPP/14-005] [Medline: 24937151]

28. Chong JL, Matchar DB, Tan Y, Sri Kumaran S, Gandhi M, Ong MEH, et al. Population Segmentation Based on Healthcare Needs: Validation of a Brief Clinician-Administered Tool. J Gen Intern Med 2020 Jun 30 [FREE Full text] [doi: 10.1007/s11606-020-05962-4] [Medline: 32607929]

29. Chong JL, Low LL, Chan DYL, Shen Y, Thin TN, Ong MEH, et al. Can we understand population healthcare needs using electronic medical records? Singapore Med J 2019 Sep;60(9):446-453 [FREE Full text] [doi: 10.11622/smedj.2019012] [Medline: $\underline{30644525]}$

30. Yan S, Seng BJJ, Kwan YH, Tan CS, Quah JHM, Thumboo J, et al. Identifying heterogeneous health profiles of primary care utilizers and their differential healthcare utilization and mortality - a retrospective cohort study. BMC Fam Pract 2019 Apr 23;20(1):54 [FREE Full text] [doi: 10.1186/s12875-019-0939-2] [Medline: 31014231]

31. Vuik SI, Mayer E, Darzi A. A quantitative evidence base for population health: applying utilization-based cluster analysis to segment a patient population. Popul Health Metr 2016 Nov 25;14:44 [FREE Full text] [doi: 10.1186/s12963-016-0115-z] [Medline: 27906004]

32. Agboola S, Simons M, Golas S, Op den Buijs J, Felsted J, Fischer N, et al. Health Care Cost Analyses for Exploring Cost Savings Opportunities in Older Patients: Longitudinal Retrospective Study. JMIR Aging 2018 Aug 01;1(2):e10254 [FREE Full text] [doi: 10.2196/10254] [Medline: $\underline{31518241]}$

33. Orozco-Beltran D, Sánchez-Molla M, Sanchez JJ, Mira JJ, ValCrònic Research Group. Telemedicine in Primary Care for Patients With Chronic Conditions: The ValCrònic Quasi-Experimental Study. J Med Internet Res 2017 Dec 15;19(12):e400 [FREE Full text] [doi: 10.2196/jmir.7677] [Medline: 29246881]

34. Eissens van der Laan MR, van Offenbeek MAG, Broekhuis H, Slaets JPJ. A person-centred segmentation study in elderly care: towards efficient demand-driven care. Soc Sci Med 2014 Jul;113:68-76 [FREE Full text] [doi: 10.1016/j.socscimed.2014.05.012] [Medline: 24852657]

35. Smeets RGM, Elissen AMJ, Kroese MEAL, Hameleers N, Ruwaard D. Identifying subgroups of high-need, high-cost, chronically ill patients in primary care: A latent class analysis. PLoS One 2020;15(1):e0228103 [FREE Full text] [doi: 10.1371/journal.pone.0228103] [Medline: 31995630]

36. Rijken M, van der Heide I. Identifying subgroups of persons with multimorbidity based on their needs for care and support. BMC Fam Pract 2019 Dec 27;20(1):179 [FREE Full text] [doi: 10.1186/s12875-019-1069-6] [Medline: $\underline{31881942]}$

37. Rees S, Williams A. Promoting and supporting self-management for adults living in the community with physical chronic illness: A systematic review of the effectiveness and meaningfulness of the patient-practitioner encounter. JBI Libr Syst Rev 2009;7(13):492-582. [doi: 10.11124/01938924-200907130-00001] [Medline: 27819974]

38. Poitras M, Maltais M, Bestard-Denommé L, Stewart M, Fortin M. What are the effective elements in patient-centered and multimorbidity care? A scoping review. BMC Health Serv Res; 18(1). 2018. URL: https://doi.org/10.1186/s12913-018-3213-8 [accessed 2020-07-14]

39. IDF Diabetes Atlas, 9th edn. Brussels: International Diabetes Federation; 2019. URL: https://www.diabetesatlas.org [accessed 2020-10-15]

40. Shaw JE, Sicree RA, Zimmet PZ. Global estimates of the prevalence of diabetes for 2010 and 2030. Diabetes Res Clin Pract 2010 Jan;87(1):4-14. [doi: 10.1016/j.diabres.2009.10.007] [Medline: 19896746]

41. Nam S, Chesla C, Stotts NA, Kroon L, Janson SL. Barriers to diabetes management: patient and provider factors. Diabetes Res Clin Pract 2011 Jul;93(1):1-9. [doi: 10.1016/j.diabres.2011.02.002] [Medline: 21382643]

42. Sina M, Graffy J, Simmons D. Associations between barriers to self-care and diabetes complications among patients with type 2 diabetes. Diabetes Res Clin Pract 2018 Jul;141:126-131 [FREE Full text] [doi: 10.1016/j.diabres.2018.04.031] [Medline: 29689320]

43. Mokkink LB, Terwee CB, Patrick DL, Alonso J, Stratford PW, Knol DL, et al. The COSMIN study reached international consensus on taxonomy, terminology, and definitions of measurement properties for health-related patient-reported outcomes. J Clin Epidemiol 2010 Jul;63(7):737-745. [doi: 10.1016/j.jclinepi.2010.02.006] [Medline: 20494804] 
44. Terwee CB, Prinsen CAC, Chiarotto A, Westerman MJ, Patrick DL, Alonso J, et al. COSMIN methodology for evaluating the content validity of patient-reported outcome measures: a Delphi study. Qual Life Res 2018 May;27(5):1159-1170. [doi: 10.1007/s11136-018-1829-0] [Medline: 29550964]

45. Dawson J, Doll H, Fitzpatrick R, Jenkinson C, Carr AJ. The routine use of patient reported outcome measures in healthcare settings. BMJ 2010;340:c186. [Medline: 20083546]

46. Garin O, Ayuso-Mateos JL, Almansa J, Nieto M, Chatterji S, Vilagut G, MHADIE consortium. Validation of the 'World Health Organization Disability Assessment Schedule, WHODAS-2' in patients with chronic diseases. Health Qual Life Outcomes 2010 May 19;8:51 [FREE Full text] [doi: 10.1186/1477-7525-8-51] [Medline: 20482853]

47. Aro A, Karjalainen M, Tiihonen M, Kautiainen H, Saltevo J, Haanpää M, et al. Glycemic control and health-related quality of life among older home-dwelling primary care patients with diabetes. Prim Care Diabetes 2017 Dec;11(6):577-582 [FREE Full text] [doi: 10.1016/j.pcd.2017.07.001] [Medline: 28754430]

48. Pouwer F, van der Ploeg HM, Adèr HJ, Heine RJ, Snoek FJ. The 12-item well-being questionnaire. An evaluation of its validity and reliability in Dutch people with diabetes. Diabetes Care 1999 Dec;22(12):2004-2010 [FREE Full text] [doi: 10.2337/diacare.22.12.2004] [Medline: 10587834]

49. Saisho Y. Use of Diabetes Treatment Satisfaction Questionnaire in Diabetes Care: Importance of Patient-Reported Outcomes. Int J Environ Res Public Health 2018 May 09;15(5) [FREE Full text] [doi: 10.3390/ijerph15050947] [Medline: 29747423]

50. Type 2 Diabetes. Current Care Guidelines. Working group set by the Finnish Medical Society Duodecim and the Finnish Society of Internal Medicine, the Medical Advisory Board of the Finnish Diabetes Society. Helsinki: The Finnish Medical Society Duodecim 2020 URL: http://www.kaypahoito.fi/xmedia/hoi/hoi50056.pdf [accessed 2020-02-20]

51. Kazis LE, Anderson JJ, Meenan RF. Effect sizes for interpreting changes in health status. Med Care 1989 Mar;27(3 Suppl):S178-S189. [Medline: 2646488]

52. Sample size calculator. UBC. URL: https://www.stat.ubc.ca/ rollin/stats/ssize/n2.html [accessed 2020-07-14]

53. Braun V, Clarke V. Successful qualitative research: a practical guide for beginners. In: SAGE Publications. London: SAGE Publications; 2013:2013.

54. McHugh ML. Interrater reliability: the kappa statistic. Biochem Med (Zagreb) 2012;22(3):276-282. [Medline: 23092060]

55. Tavakol M, Dennick R. Making sense of Cronbach's alpha. Int J Med Educ 2011 Jun 27;2:53-55 [FREE Full text] [doi: 10.5116/ijme.4dfb.8dfd] [Medline: 28029643]

56. Carter N, Valaitis RK, Lam A, Feather J, Nicholl J, Cleghorn L. Navigation delivery models and roles of navigators in primary care: a scoping literature review. BMC Health Serv Res 2018 Feb 08;18(1):96 [FREE Full text] [doi: 10.1186/s12913-018-2889-0] [Medline: 29422057]

57. Manderson B, McMurray J, Piraino E, Stolee P. Navigation roles support chronically ill older adults through healthcare transitions: a systematic review of the literature. Health Soc Care Community 2012 Mar;20(2):113-127 [FREE Full text] [doi: 10.1111/j.1365-2524.2011.01032.x] [Medline: 21995806]

\section{Abbreviations}

CS group: customership strategies group

DTSQ: Diabetes Treatment Satisfaction Questionnaire

EHR: electronic health record

EQ-5D: EuroQol 5D

FHA: Finnish Heart Association

ICF: International Classification of Functioning, Disability, and Health

WHODAS 2.0: World Health Organization Disability Assessment Schedule 2.0

VAS: Visual Analog Scale

Edited by $G$ Eysenbach; submitted 22.05.20; peer-reviewed by J Leksell; comments to author 05.07.20; revised version received 25.08.20; accepted 14.09.20; published 02.11.20

Please cite as:

Riihimies R, Kosunen E, Koskela $T$

Web-Based Patient Segmentation in Finnish Primary Care: Protocol for Clinical Validation of the Navigator Service in Patients With Diabetes

JMIR Res Protoc 2020;9(11):e20570

URL: https://www.researchprotocols.org/2020/11/e20570

doi: $\underline{10.2196 / 20570}$

PMID: 33136062 
CRiikka Riihimies, Elise Kosunen, Tuomas Koskela. Originally published in JMIR Research Protocols (http://www.researchprotocols.org), 02.11.2020. This is an open-access article distributed under the terms of the Creative Commons Attribution License (https://creativecommons.org/licenses/by/4.0/), which permits unrestricted use, distribution, and reproduction in any medium, provided the original work, first published in JMIR Research Protocols, is properly cited. The complete bibliographic information, a link to the original publication on http://www.researchprotocols.org, as well as this copyright and license information must be included. 